\title{
A imagem pública nos 100 primeiros dias de governo: uma análise de entrevistas do portal G1 com prefeitos em início de mandato
}

\author{
Erivelto Diego Amarante \\ Universidade Federal do Paraná, Curitiba, PR, Brasil \\ ORCID: https://orcid.org/0000-0003-4158-3444
}

\section{Rafael Cardoso Sampaio}

Universidade Federal do Paraná, Programa de Pós-Graduação em Comunicação, Curitiba, PR, Brasil ORCID: https://orcid.org/0000-0001-5176-173X

\section{Resumo}

Os 100 primeiros dias de governo são retratados pela mídia como uma data simbólica do início de uma gestão. $O$ jornalismo tem por hábito agendar o tema em seus noticiários no decorrer do período e, de forma mais efetiva, no centésimo dia. Esse trabalho analisa a série de entrevistas do portal G1 com 28 prefeitos de capitais e regiões metropolitanas publicadas em 10 de abril de 2017, data exata dos 100 primeiros dias de gestão. Para isso, usa como referencial teórico-metodológico o estudo do enquadramento noticioso. O objetivo é identificar, a partir das entrevistas, quais saliências predominam entre os campos da mídia e da política, buscando perceber de que forma o jornalismo se apropria do marco temporal para enquadrar a entrevista; e quais saliências são percebidas nas perguntas dos jornalistas. Por outro lado, considerando a dependência dos atores políticos pela exposição midiática, também buscamos identificar, no discurso político, qual a imagem que os governantes desejam imprimir no início do mandato. Os resultados apontam que, enquanto o jornalismo usa o período para cobrar o andamento das propostas de campanha, os políticos aproveitam a efeméride para imprimir uma imagem de trabalho, realização e otimismo.

\section{Palavras-chave}

Imagem pública; Enquadramento noticioso; 100 dias de governo; Discurso político; Comunicação política 


\section{Introdução}

Diversos autores têm ressaltado a dependência crescente dos atores políticos dos meios de comunicação na tentativa de conquistar visibilidade e mobilizar a opinião pública (CHAMPAGNE, 1998; GOMES, 2004; RUBIM, 2004). Maria Helena Weber (2004) usa o termo "política estetizada" para se referir ao espaço onde sujeitos e instituições comparecem em busca de reconhecimento. Essa arena é formada pelos agentes da mídia e pela sociedade, que formula suas próprias opiniões. Esse ambiente é alvo de dúvidas e tensionamentos, o que implica mudanças e adaptações constantes visando ao processo de constituição da imagem desejada pela política e da imagem percebida pelo público.

Gomes (2004) observa que, cada vez mais, a disputa política tem se transformado numa luta pela imposição da imagem pública. Isso ocorre entre os próprios atores políticos, mas também tem a finalidade de influenciar a percepção da opinião pública sobre os interesses que se apresentam na cena política. A criação e a circulação das imagens são vistas por muitos como um dos fenômenos de maior interesse no contexto político contemporâneo e nascem numa associação entre os atores desse campo com o jornalismo político.

Uma das estratégias usadas pelas autoridades para atrair a atenção da mídia é o "pseudoevento", quando eventos são criados em busca de visibilidade (KEPPLINGER, 2015). A própria efeméride dos 100 dias é usada com essa finalidade. João Doria, por exemplo, participou de um evento na Prefeitura de São Paulo para lembrar da data e convocou a imprensa para promover as primeiras iniciativas de sua gestão. Boorstin (2012) entende que esses acontecimentos são considerados como ilhas artificiais construídas no fluxo das ocorrências captadas por jornalistas.

O jornalismo costuma tratar os 100 primeiros dias de mandato como um marco importante do início de um governo, seja ele presidente, governador ou prefeito. Prova disso é uma série de entrevistas do portal G1, publicada em 10 de abril de 2017, data exata do centésimo dia, com 28 prefeitos de capitais e regiões metropolitanas, eleitos ou reeleitos na eleição municipal de outubro de 2016. Com o título "Prefeitos falam sobre 100 dias de gestão", o veículo sinaliza que as entrevistas foram agendadas em torno desse marco temporal.

Este artigo transita entre os campos da mídia e da política. Em relação à motivação do primeiro, Lage (2014, p. 21) afirma que o jornalista deve "saber selecionar o que 
interessa e é útil ao público" e ser "verdadeiro quanto aos fatos". Quanto ao segundo, Charaudeau (2006) entende que a linguagem é uma das expressões da ação política. Por meio dela, seus atores buscam satisfazer os anseios dos cidadãos. Diante disso, o objetivo central deste estudo é identificar, a partir das diferenças e semelhanças percebidas nas entrevistas, quais saliências predominam na relação entre a mídia (perguntas) e a política (respostas). Com isso, buscamos entender como o jornalismo e os governantes fazem uso da efeméride dos 100 dias de governo para atender às expectativas da sociedade.

Trabalhamos com duas hipóteses. A primeira considera as perguntas dos jornalistas. Nesse caso, acreditamos que (H1) foram salientados temas envolvendo a cobrança de resultados em torno das propostas apresentadas na campanha eleitoral, apresentando elementos contrários à imagem desejada pelos políticos. A segunda leva em conta as respostas dos prefeitos. Desse modo, esperamos que (H2) os atores políticos tenham aproveitado o espaço para promover a própria imagem, projetando um clima positivo para o início da gestão.

Para testar nossas hipóteses, analisamos todas as 28 entrevistas ${ }^{1}$ publicadas no portal G1, em 10 de abril de 2017, por ocasião dos 100 dias de governo. Ao todo, foram ouvidos 12 prefeitos de capitais e 16 prefeitos de regiões metropolitanas, distribuídos em 13 estados brasileiros. Para a análise, usamos como referencial teórico-metodológico o enquadramento noticioso. Maia (2009) considera que os agentes da mídia "editam e conferem proeminência diferenciadas às vozes dos atores sociais, hierarquizam discursos em seus textos e, assim, enquadram sentidos" (MAIA, 2009, p. 304). De modo geral, o enquadramento enfatiza certos aspectos da realidade e obscurece outros (ENTMAN, 1993).

Na literatura, o news frame já serviu de arcabouço para uma série de estudos no campo da comunicação política. Entre alguns exemplos, é possível citar o debate sobre o referendo de armas de fogo no país (CAMPOS, 2014), a repercussão sobre o sequestro da jovem Eloá pelo ex-namorado (FRANÇA, 2009) e a cobertura do processo de impeachment de Dilma Rousseff (RIZZOTO; PRUDENCIO; SAMPAIO, 2017).

Este trabalho está estruturado da seguinte forma: o tópico a seguir trata da importância da imagem na política; em seguida, abordamos os aspectos que marcam a lógica

\footnotetext{
1 Foram publicadas entrevistas com os(as) prefeitos(as) dos seguintes municípios: Aracaju (SE), Bauru (SP), Boa Vista (RR), Curitiba (PR), Diadema (SP), Duque de Caxias (RJ), Florianópolis (SC), Guarulhos (SP), Itapetininga (SP), Maceió (AL), Mauá (SP), Mogi das Cruzes (SP), Palmas (TO), Porto Alegre (RS), Niterói (RJ), Osasco (SP), Ribeirão Preto (SP), Rio de Janeiro (RJ), Salvador (BA), Santarém (PA), São Bernardo do Campo (SP), São José do Rio Preto (SP), São José dos Campos (SP), São Paulo (SP), Santo André (SP), Sorocaba (SP), Teresina (PI) e Vitória (ES).
} 
da mídia e também a linguagem e o discurso político; depois, nos debruçamos sobre o contexto em torno dos 100 dias de governo. Por fim, apresentamos os detalhes sobre o enquadramento noticioso, a técnica usada para a coleta dos dados, os resultados da pesquisa empírica e a discussão dos nossos achados. A última parte propõe ainda novas abordagens para estudos futuros.

\section{Política e imagem}

Hoje, o que prevalece no campo político é a conviçção de que grande parte da disputa política se constitui numa competição não apenas pela construção, mas também pelo controle da imagem dos indivíduos, grupos e instituições participantes do jogo do poder. Essa batalha é constante, não se resumindo ao período eleitoral, e perpassando a esfera governamental, legislativa, dos partidos e tudo que se relaciona com a esfera pública deliberativa e a busca pela preservação dos espaços de poder. Gomes (2004) é enfático ao afirmar que é nessa arena que se definem as preferências eleitorais, que se estabelecem elos com a sociedade e o mercado financeiro e que se constroem as condições de governabilidade.

O protagonismo da imagem pública vai além das relações cotidianas da política e alcança o que Gomes (2004) considera como um "complexo jogo de papéis, status e posições relativas e sociais, que constituem qualquer forma de sociedade" (GOMES, 2004, p. 243). Hannah Arendt (1993) lembra que tudo se dirige ao espectador, considerado o principal sujeito de formação da imagem. Ela ressalta que "somente o espectador, e nunca o ator, pode conhecer e compreender o que quer que se ofereça como espetáculo" (ARENDT, 1993, p. 72).

Na condição de espectador, o sujeito tem papel ativo como elemento capaz de tencionar as relações entre os poderes. Para Weber (2004, p. 262), esse sujeito pode "avaliar, intermediar e criticar o movimento dos poderes e, também, usufruir da estetização da política, numa espécie de acordo momentâneo, entre o desejo e a proposta". Para ela, a imagem pública é "conceitual e visual, individual e social, real e abstrata. Junto se mantém a dúvida permanente sobre a verdade veiculada, pois o discurso político sempre inclui o adversário" (WEBER, 2004, p. 263).

A imagem pública de um indivíduo é formada por uma complexa rede de informações, noções e conceitos partilhados por uma coletividade. Assim, imagens públicas 
são "concepções caracterizadoras" (GOMES, 2004, p. 254). Uma certeza é que ela é incerta, não é fixa nem estável. Ao contrário, imagens podem deixar de existir, alterar-se e reconstruir-se. Gomes (2004, p. 255) lembra que temos sempre que ver como "imagem de" e não como algo absoluto. Na política, a imagem pública é construída por um conjunto de técnicos e gerenciadores que se situam do lado da emissão das mensagens. Diante disso, a instância geradora da imagem é a subjetividade humana. Assim, a influência dos meios de comunicação se torna particularmente visível.

Weber (2000) cita a existência de modelos voltados para a interação entre os atores políticos e a mídia. 0 primeiro deles é o modelo editorial e agrega eventos que a mídia constrói como espetáculo político. 0 modelo articulado ocorre na interação entre mídia e política. 0 modelo autônomo diz respeito a um fato político excepcional capaz de mudar o padrão da cobertura. Por fim, o tipo arbitrário se refere ao controle do espaço-tempo da mídia pelo campo da política (WEBER, 2000, p. 107).

A mudança pela qual atravessa a comunicação política envolve o surgimento, a adaptação e a inovação dos formatos de comunicação associados a conteúdos mais voltados para o entretenimento (ALTHEIDE, 2013; RUBIM, 2004). A cultura política é afetada por esses formatos em expansão, já que os jornalistas e as fontes de notícias usam recursos visuais, linguagem e drama para atrair e conquistar o público. Mazzoleni e Schulz (1999) ressaltam que a melhor descrição da situação atual é a "midiatização", que leva a um deslocamento gradual da lógica política através da lógica da mídia. Isto posto, tratamos a seguir dos pactos entre os agentes da mídia e da política envolvidos nesse processo.

\section{Midiatização da política}

Rubim (2004) usa o termo "midiapolítica" para se referir ao fenômeno da política midiatizada. Ele ressalta que muitos autores atribuem a mídia, em especial a televisão, como um espaço privilegiado da luta política contemporânea. Dessa forma, a política vem apresentando alterações consideráveis por conta da necessidade de se adequar à dinâmica do novo espaço eletrônico através da adoção de linguagens e dos recursos midiáticos, o que ficou conhecido como procedimento de midiatização. Por sua vez, a mídia também adota novas rotinas de produção diante das tecnologias e novos padrões de cobertura do cotidiano político. 
A lógica da mídia não está voltada para um tipo específico, como a televisão, nem é um processo "unilinear" (BRANTS; VAN PRAAG, 2006). O conceito trata das suposições e processos para a construção de mensagens que inclui ritmo, gramática e formato. Portanto, cada meio está associado ao seu próprio código de interpretação que os membros do público reconhecem e a partir do qual podem distinguir, por exemplo, um telejornal de um programa de humor. Assim, os membros da audiência adotam seletivamente esse sistema geral de lógica e símbolos para compreender a experiência da mídia.

Grande parte dos estudos sobre a lógica da mídia abordam uma perspectiva interacionista simbólica sobre a natureza do significado e a construção social da realidade (BLUMER, 1986). Nesse sentido, Blumer (1986) sugere que os membros da audiência interagem com a mídia, e vice-versa, para desenvolver significados baseados nos símbolos empregados e interpretados em um contexto específico. Portanto, a ordem social está cada vez mais mediada e a ação social passa a ser moldada e informada pelas tecnologias da mídia e pelas lógicas que orientam o comportamento e as percepções.

Miguel (2002) observa que as relações entre a mídia e a política não se reduzem a um jogo entre domínio e submissão, mas se revelam complexas. Dessa forma, são mediadas por tensões, barganhas e negociações constantes entre as partes. Assim, mídia e política "guardam certo grau de autonomia e a influência de um sobre o outro não é absoluta nem livre de resistências" (MIGUEL, 2002, p. 167). Nessa perspectiva, a análise das entrevistas nos permite verificar como os dois campos interagem em torno dos 100 dias. Conforme apresentaremos na sequência, a interação dos prefeitos com os jornalistas se dá em grande parte pelo uso da linguagem e do discurso político.

\section{Linguagem e discurso político}

Os recursos visuais e a linguagem são parte importante da construção da retórica política, uma estratégia usada para promover os interesses dentro da espera pública (COE, 2015). De forma mais frequente, a retórica é entendida e estudada como mensagens públicas persuasivas que emanam de ou para aqueles em posições de liderança. Um dos modos mais comuns de estudar a retórica política é categorizar seu conteúdo, que geralmente se concentra na identificação de estilos ou gêneros.

O cientista político Murray Edelman (1994) descreveu quatro estilos distintos associados ao processo governamental: a exortação, que é o tipo de linguagem usada para 
fazer apelos a um público de massa; o legal, que trata de comandos e definições normativas; o administrativo, que geralmente vem de funcionários públicos ou nomeados; e a barganha, que é a menos pública, voltada para fazer acordos negociados em conjunto, em oposição a apelos mais formais (EDELMAN, 1994, p. 235). Por sua vez, a retórica política é o resultado de uma série de forças concorrentes que, muitas vezes, não podem ser controladas pelo orador. No caso deste estudo, o prefeito entrevistado não tem como prever quais perguntas serão feitas pelos jornalistas.

Para Charaudeau (2006), linguagem e ação são dois componentes da troca social. Embora tenham uma autonomia própria, ao mesmo tempo se encontram em uma relação de independência recíproca e não assimétrica. Em termos de instâncias implicadas na ação, a instância política assume a realização do exercício do poder e a instância cidadã cuida da escolha dos representantes. Assim, os detentores da ação política devem deliberar em função do possível, considerando que a instância cidadã os elegeu para realizar o desejável (CHARAUDEAU, 2006). Nessa perspectiva, os prefeitos ouvidos em início de mandato tendem a usar o discurso para satisfazer os anseios da população levando em conta os propósitos para os quais foram eleitos.

Sánchez Galicia (2010) argumenta que os atores políticos podem usar palavras de maneira que os significados se expandam com o objetivo de incluir, engajar e mobilizar. Portanto, é preciso considerar também a força por trás da escolha de determinadas expressões. Palavras como "progresso" e "liberdade" podem reforçar uma frase política e dar a ela um significado afirmativo. A linguagem sofre influência e contestação de candidatos, eleitos, jornalistas, ativistas e cidadãos, que transmitem e recebem mensagens políticas todos os dias. Como veremos a seguir, o marco em torno dos 100 dias de governo se transformou em um lócus para a circulação e a disputa desses discursos na esfera pública.

\section{Os 100 dias de governo}

Segundo Neustadt (2001), Franklin D. Roosevelt foi o primeiro presidente dos Estados Unidos a usar o termo 100 dias de governo. Ao assumir o cargo, em 4 de março de 1933, Roosevelt havia sinalizado sua intenção de avançar com medidas para combater os efeitos da Grande Depressão. Ao comemorar o sucesso de tais iniciativa em um discurso de rádio, em 24 de julho daquele ano, ele cunhou o termo "primeiros 100 dias". Desde então, o 
período passou a ser uma referência para medir o sucesso inicial de um governante em início de mandato (NEUSTADT, 2001).

A literatura norte-americana usa os primeiros 100 dias de governo como referência para medir principalmente a força do presidente recém-eleito no Congresso. Dominguez (2005) verificou que as taxas de aprovação de pautas de interesse do Executivo durante o ano inaugural são maiores (87\%), em média, do que nos anos seguintes (65\%). Também é possível encontrar estudos sobre a cobertura noticiosa. Hughes (1995) fez uma análise de conteúdo das manchetes de primeira página do New York Times e concluiu que Clinton recebeu uma cobertura hostil devido ao fato de que muitas de suas promessas de campanha o deixaram "preso a uma agenda complexa e muitas vezes contraditória" (HUGHES, 1995, p. 848).

No Brasil, ainda existem poucos estudos que tratam especificamente dos primeiros 100 dias de governo. Castanhar (1990) usou o período para fazer uma análise econômica do início do mandato do ex-presidente Fernando Collor sobre a reforma administrativa. No campo da comunicação, Borges (2008) estudou a cobertura do governo Lula durante o início de seu segundo mandato nas versões online de 0 Globo e Jornal do Brasil. Seu objetivo era verificar como os jornais trataram do início do mandato em suas coberturas. Para ele, o marco vem sendo adotado "como meio de acompanhar os movimentos políticos do governo recém-empossado, na tentativa de identificar formas peculiares de funcionamento capazes de sinalizar como será o mandato" (BORGES, 2008, p. 1).

Levando em conta a lógica da mídia durante a cobertura jornalística dos 100 dias de governo, Borges (2008) ressalta que as pautas estão normalmente relacionadas ao cotidiano da política e o agendamento "opera segundo uma temporalidade aberta porque os objetivos e movimentos políticos não estão pré-condicionados a uma agenda dada, como em processos eleitorais" (BORGES, 2008, p. 3). Na visão do autor, nesse período, o jornalismo não precisa se restringir a cobertura de um evento ou acontecimento pontual, já preso a um determinado contexto político, tendo assim ampla liberdade de seleção do que será divulgado.

Ao realizarmos uma breve pesquisa com o termo "100 dias de governo" na internet, é possível encontrar uma série de notícias relacionadas sobre o tema em páginas de diferentes veículos de comunicação, como em jornais (O GLOBO, 2017) e emissoras de rádio (CBN, 2021). Por outro lado, a busca também aponta para páginas oficiais de governos (PREFEITURA DE ARACRUZ, 2017) que repercutem assuntos relacionados ao marco 
temporal. Esse fato demonstra que a efeméride é aceita tanto pelo campo da mídia como pelo da política. Isso posto, apresentamos a seguir os aspectos metodológicos e os resultados da pesquisa.

\section{Metodologia}

Vários autores (ENTMAN, 1993; MAIA, 2009; PORT0, 2007) destacam, dentro de uma teoria de mediação abrangente, que a mídia não apenas ajuda a moldar e guiar o conteúdo e diversas atividades da vida cotidiana, como também faz com que os públicosatores normalizam essas formas e passam a usá-los como ferramentas de manutenção da realidade. Essa dinâmica também é sentida na política. 0 agendamento dos 100 dias de mandato fez com que alguns governos adotassem o período como marco para a definição de suas políticas e estratégias. A título de exemplo, Jair Bolsonaro, antes mesmo de assumir a presidência, divulgou uma cartilha (ESTADÃO, 2018) com metas prioritárias para o período.

Diante do fenômeno da midiatização, o nosso objetivo é identificar, a partir das diferenças e semelhanças percebidas na cobertura dos 100 dias de governo, quais saliências predominaram entre os campos da mídia e da política. Para isso, vamos considerar as 28 entrevistas com prefeitos de regiões metropolitanos e do interior publicadas no portal G1em 10 de abril de 2017, data exata do período. A escolha do objeto deu-se por se tratar do principal portal de notícias do Grupo Globo, o maior conglomerado de mídia do país.

Trabalhamos neste artigo com duas hipóteses. A primeira, no campo do jornalismo, acredita que (H1) a cobertura priorizou temas envolvendo a cobrança de resultados em torno das propostas eleitorais, desafiando a imagem desejada pelos prefeitos. A segunda, no campo da política, entende que (H2) os governantes usaram o espaço para promover a própria imagem, tentando criar um clima positivo do início da gestão.

Para a análise das entrevistas, utilizamos como metodologia o enquadramento noticioso. Para Entman (1993, p. 51), “o enquadramento oferece um caminho para descrever o poder do texto comunicacional e sua influência sobre a consciência humana, exercida pela transferência da informação". Para Mendonça e Simões, nesta linha de pesquisa dentro do campo do enquadramento, "é no conteúdo que se busca o quadro, visto como uma espécie de ângulo, que permite compreender uma interpretação proposta em detrimento de outras" (MENDONÇA; SIMÕES, 2012, p. 194). 
Entre alguns exemplos, Fernandes, Oliveira e Quadros (2021) usaram o enquadramento para entender como a jornalista e escritora Eliane Brum enquadrou Jair Bolsonaro em seus artigos no jornal El País entre a eleição presidencial de 2018 e os 100 dias de governo. Os autores concluíram que Brum adotou um tom panfletário em suas críticas contra Bolsonaro e assumiu a posição do jornalismo como ator social. Amarante (2021) analisou os 100 dias de mandato de João Doria na Prefeitura de São Paulo nos jornais Folha de S.Paulo e Estadão e concluiu que houve diferenças na cobertura. Enquanto a Folha adotou um tom crítico e de contestação, o diário concorrente seguiu uma linha mais favorável à imagem de Doria.

Para a análise aqui proposta, o conteúdo textual foi dividido em dois grupos: o que considera apenas as perguntas, cuja origem é o jornalismo, e o que considera apenas as respostas, cuja origem são os atores políticos ou os prefeitos. Assim, será possível perceber, no primeiro caso, os componentes enquadrados pelo veículo tendo como referência o arcabouço teórico-metodológico do enquadramento noticioso (ENTMAN, 1993; MAIA, 2009, PORTO, 2007) e, no segundo caso, como os prefeitos fazem uso do discurso político (CHARAUDEAU, 2006) para construir a imagem pública mais favorável para os 100 primeiros dias de governo (GOMES, 2004; WEBER, 2004).

\section{Resultados}

A série de entrevistas do G1 promete ouvir os prefeitos das "principais cidades de regiões metropolitanas e interior do país". Contudo, um panorama mais amplo do corpus indica que esse não foi o principal critério usado para a seleção de quais prefeitos seriam entrevistados. 0 Brasil possui 74 regiões metropolitanas definidas por leis estaduais e federais. Destas, apenas 19 foram contempladas nas sabatinas.

A maior parte dos prefeitos ouvidos era do Sudeste. Só nessa área, foram entrevistados 18 prefeitos, 15 deles de regiões metropolitanas de São Paulo e Rio de Janeiro. Os municípios da Grande $\mathrm{ABC}$, como Santo André e São Bernardo do Campo, foram priorizados nas sabatinas. Por sua vez, Campinas, segunda maior região do estado, e Santos, polo econômico e turístico, não receberam espaço.

Também chamou atenção o fato de que nenhum prefeito de Minas Gerais, estado com o maior número de municípios do país, foi ouvido. Enquanto o G1 entrevistou os 
gestores das três capitais da região Sul, nenhum prefeito do Centro-Oeste foi considerado, sendo a única região do país não representada na série de entrevistas.

Um panorama mais amplo do corpus revelou ainda que a maior parte dos prefeitos (71\%) estava no primeiro mandato, o que indica um interesse maior em conhecer os novos gestores. Quando o assunto é representação feminina, das 28 gestões municipais, apenas duas eram comandadas por mulheres, o que corresponde a $7 \%$ do total.

Também comparamos o número de perguntas e o espaço ocupado em caracteres nas entrevistas para cada partido político. Para os partidos com mais de um prefeito, calculamos a média. Conforme o Gráfico 1, o PSDB foi a legenda com o maior número de políticos ouvidos pelo G1, 10 ao todo, correspondendo a $36 \%$ do total.

Gráfico 1 - Prefeitos por partido, perguntas e espaço ocupado

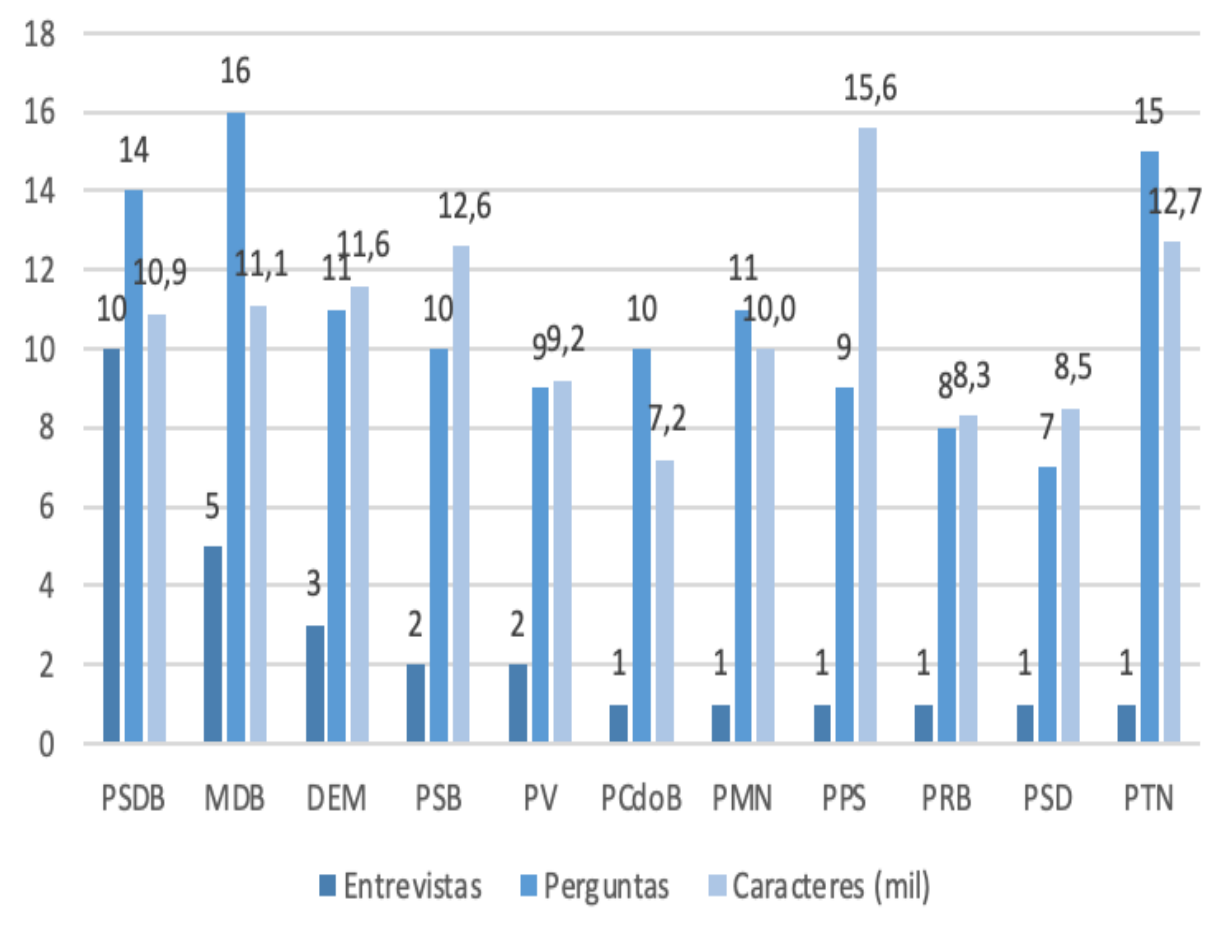

Fonte: Elaborado pelos autores.

De acordo com os resultados do TSE, em 2016, os tucanos cresceram 15,6\% no número de prefeituras em relação ao pleito anterior. Muitas dessas cidades eram administradas pelo PT, que elegeu 59,4\% menos prefeitos que em 2012, tendo perdido o comando de Guarulhos, São Paulo e São Bernardo do Campo para seu maior rival. O segundo partido com mais entrevistados foi o MDB, com cinco, seguido pelo DEM, com três, e o PSB e 
PV, com dois cada. Os partidos PCdoB, PMN, PPS, PRB, PSD e PTN tiveram um prefeito ouvido cada.

À esquerda (CODATO; BERLATTO; BOLOGNESI, 2018), o PSB teve mais exposição, com três prefeitos ouvidos. Outro partido do campo considerado foi o PCdoB, com Edvaldo Nogueira, de Aracaju. Além do PT, chama a atenção o fato do G1 não ter ouvido nenhum prefeito do PDT, que venceu a eleição em Fortaleza (CE), Natal (RN) e São Luís (MA). À direita, partidos tradicionais como o PP e o PR, no bloco dos dez com o maior número de prefeituras do país, também não ganharam espaço nas sabatinas do G1.

Em relação ao número de perguntas, observou-se um certo equilíbrio quando consideramos a média dos prefeitos de cada partido. Contudo, os gestores do MDB, PTN e PSDB foram mais indagados. Em relação ao espaço, medido em caracteres (por mil), os partidos com um único representante conseguiram resultados melhores, como o PPS e PTN, isso porque a média reduziu as margens de PSDB e MDB, que registraram maior oscilação entre os entrevistados.

Quando consideramos os casos individualmente, o resultado aponta para um desequilíbrio no espaço dedicado aos prefeitos. Enquanto os gestores de Niterói (RJ), Rodrigo Neves (PV), de Santarém (PA), Nélio Aguiar (MDB), e do Rio de Janeiro, Marcelo Crivella (PRB), tiveram menos de oito mil caracteres de exposição, os prefeitos de Mogi das Cruzes (SP), Marcus Melo (PSDB), Sorocaba (SP), José Crespo (DEM), e Guarulhos (SP), Gustavo Henric Costa (PSDB), tiveram mais do que o dobro de espaço. 0 número de perguntas também variou, entre sete e 21 .

Os estudos de enquadramento noticioso buscam evidenciar de que maneira elementos ganham saliência na cobertura jornalística em detrimento de outros (ENTMAN, 1993). Para identificar quais temáticas receberam mais atenção do G1 nas entrevistas, foram separados do texto apenas as perguntas, o que resultou num corpus de 397 itens. Em seguida, foi usado o serviço online WriteWords (202-), que faz a contagem do número de cada palavra descrita no texto. Por fim, as palavras mais utilizadas foram agrupadas por áreas relacionadas para identificar quais componentes ganharam maior destaque nas sabatinas.

Conforme o Gráfico 2, os resultados dos componentes enquadrados nas perguntas dos jornalistas mostram que o portal usou o marco temporal do início do mandato para cobrar medidas e ações propostas anteriormente pelos prefeitos. Perguntas relacionadas a prazos de entregas e definição de políticas aparecem no topo da lista, com 83 menções. 
Outra saliência verificada foi em relação ao cumprimento de promessas de campanha (63) e aos planos (50) em andamento. A preocupação com os gastos públicos também foi evidenciada no item orçamento (29), assim como os impostos (17).

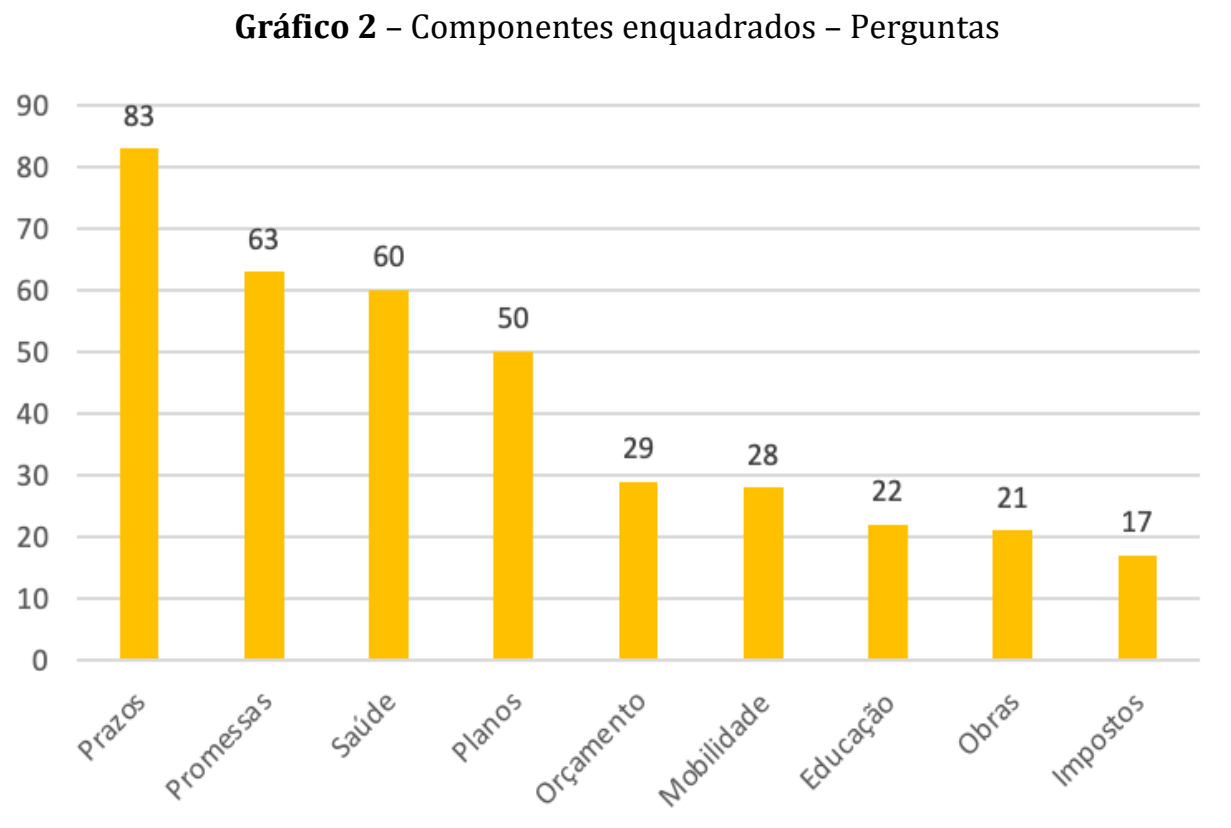

Fonte: Elaborado pelos autores.

Uma das semelhanças percebidas em todas as perguntas eram assuntos relacionados com as propostas de campanha, principalmente dos gestores recém-eleitos. Para os reeleitos, as perguntas mais recorrentes faziam referência a declarações anteriores e cobravam prazos e andamento de obras. Outra preocupação dos jornalistas era com os recursos para cumprir os compromissos assumidos. Rui Palmeira, prefeito de Alagoas (PSDB), havia proposto adquirir 10 mil livros para ampliar o acervo das bibliotecas. Diante disso, o jornalista questionou de onde sairia o dinheiro: "O recurso para adquirir os livros é do governo federal ou próprio?".

Percebemos que as entrevistas não seguiram um roteiro pré-determinado e padronizado pela equipe de jornalismo do G1, ficando a critério das equipes locais o agendamento das perguntas de acordo com o contexto de cada cidade. Em Boa Vista, uma das questões era a preocupação com a imigração de venezuelanos. Em Florianópolis, a construção de um elevado e o programa de rondas de vigilância 24h. Já em Maceió, uma das dúvidas tratava da despoluição do Riacho Salgadinho. 
Em relação às áreas específicas da administração pública, o veículo deu mais atenção para as pastas da saúde (60), mobilidade urbana (28), educação (22) e obras (21). Não houve uma padronização em relação ao número de perguntas, variando entre sete (Bauru) e 21 (Mogi das Cruzes). Em quatro casos (Duque de Caxias, Niterói, Ribeirão Preto e Rio de Janeiro), foram colocados apenas algumas declarações entre aspas ao longo do texto. $\mathrm{Ou}$ seja, o formato do texto era de uma matéria, não de uma entrevista com perguntas e respostas (LAGE, 2006).

A mesma técnica usada para identificar as temáticas das perguntas foi aplicada para as respostas. Considerando nossa segunda hipótese, o objetivo foi verificar quais assuntos os atores políticos priorizaram em seus discursos. Conforme o Gráfico 3, a maior preocupação dos prefeitos era a área da saúde, com 229 menções relacionadas. Na sequência, o termo população (175) mostra que as autoridades estavam preocupadas em dar respostas aos cidadãos, principalmente no que diz respeito ao atendimento de serviços públicos.

Gráfico 3 - Tópicos mais citados - Respostas

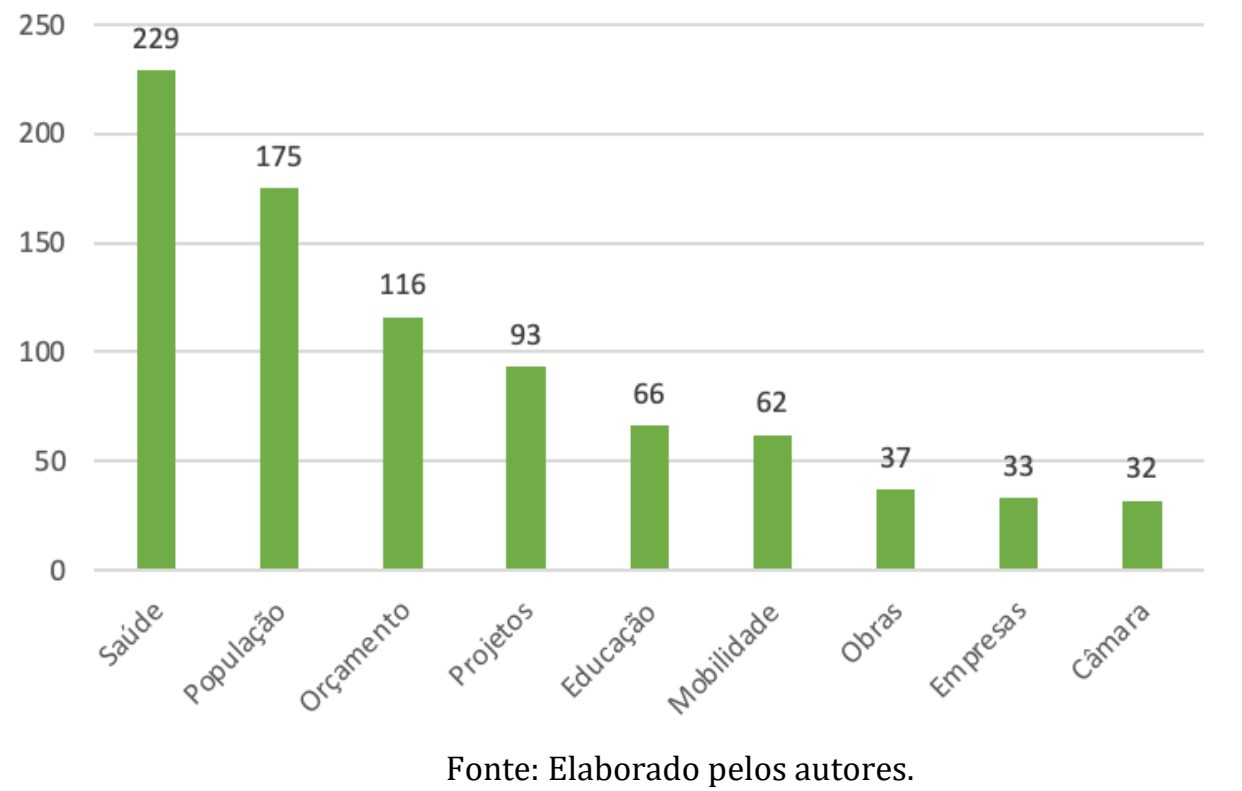

O início da gestão num momento de crise econômica no país gerou o uso de termos relacionados ao corte de gastos e a obtenção de recursos, que entraram no item orçamento (116). Os projetos em andamento e futuros também foram muito citados (93), assim como 
as áreas da educação, mobilidade urbana e obras. Por fim, a preocupação com empresas (33) e a aprovação de medidas na Câmara (32) completaram a lista.

Os prefeitos buscaram pelo discurso dar respostas contundentes sobre o desempenho de suas gestões. Ao ser indagado sobre a proposta de revogar o aumento do IPTU, o Prefeito de Aracaju, Edvaldo Nogueira (PCdoB), afirmou que "o cumprimento da promessa já foi iniciado". Sobre o projeto de construção de creches, Gean Loureiro (PMDB), prefeito de Florianópolis, mostrou-se confiante: “É um compromisso que nós vamos cumprir, no decorrer dos quatro anos, buscando inovar nessa forma de gestão".

Ao observamos as respostas dos prefeitos, percebemos a preocupação dos atores políticos em tentar projetar uma imagem positiva do início da gestão, valorizando características pessoais como a competência e o trabalho. No esforço de mostrar-se num papel ativo, até neologismos foram criados. João Doria declarou que havia sido eleito para "prefeitar" a capital paulista, e que era isso que estava fazendo. Outra estratégia era culpar o antecessor para se defender de críticas, alegando não ter influência sobre o orçamento que passou a administrar.

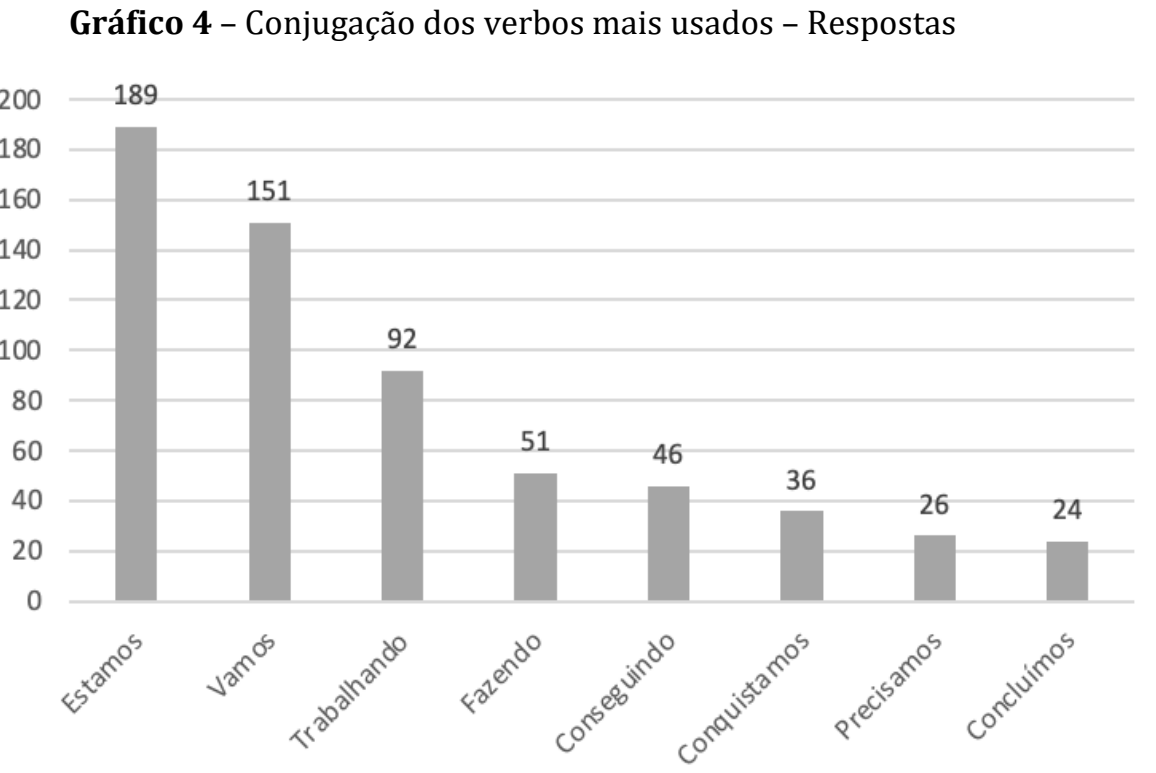

Fonte: Elaborado pelos autores.

Além de verificar quais as temáticas mais citadas pelos prefeitos em suas declarações, também coletamos os verbos mais conjugados nos discursos. Com isso, nossa intenção foi identificar, a partir de expressões que designam ação, os verbos que mais 
predominaram. Conforme o Gráfico 4, o resultado apontou que as conjugações mais comuns têm como meta discursiva a tentativa de mostrar uma imagem de trabalho e realizações no início do mandato. "Estamos" foi o mais utilizado, com 189 menções, seguido de "vamos", com 151, "trabalhando", com 92, e "fazendo", com 51.

Também aparecem expressões que remetem a resultados positivos como "conseguindo", com 46, "conquistamos", com 36, e "concluímos", com 24 menções. Chama a atenção que a conjugação dos verbos em sua maioria aparece no gerúndio, o que demonstra uma ação em andamento, ou seja, que os prefeitos estão em atividade para cumprir as funções demandadas nas urnas e pela imprensa. Em resposta sobre suas ações nos 100 dias de mandato, o prefeito reeleito de Diadema, Lauro Michels (PV), não poupou o uso de verbos: "Nós criamos e fizemos ainda mais [do que o governo anterior]. Fizemos agora, concluímos, vamos concluir no $100^{\circ}$ dia, várias ações muito importantes para a cidade".

Devido ao fato de o G1 ter seu conteúdo local abastecido por emissoras afiliadas da TV Globo, algumas das entrevistas foram transmitidas nos telejornais e depois transcritas para o portal. Portanto, houve também a mudança de formatos ou tipos de mídia, o que influenciou o próprio comportamento dos prefeitos e as suas respostas, uma vez que a televisão tem um alcance maior e uma gramática específica. Outras entrevistas foram feitas em vídeo, mas exclusivamente para o G1, como a dos prefeitos de São Paulo e Rio de Janeiro. Os recursos multimídia também foram desiguais. Nem todos tiveram fotos publicadas.

\section{Considerações finais}

Como já estabelecida pela literatura do enquadramento noticioso, não se trata de verificar apenas o que está saliente nos enquadramentos, a não cobertura pode privilegiar certos segmentos ao não dar espaço para determinados fatos, instituições ou atores políticos. Nesse sentido, a série de entrevistas do G1 com prefeitos em início de mandato privilegiou determinados políticos e partidos em detrimento de outros, que não receberam espaço no portal. É o caso de partidos mais à esquerda como o PDT e a Rede. Embora governando capitais em regiões metropolitanas, eles não tiveram a mesma exposição no portal que outras legendas, o mesmo valendo para o PT, maior partido de esquerda no momento das entrevistas em tela. Da mesma forma, partidos mais à direita, como o PP e o PR, também foram silenciados pelo G1. Por outro lado, PSDB e MDB foram favorecidos pela 
cobertura, tendo o maior número de prefeitos ouvidos. Contudo, não percebemos um direcionamento nas perguntas a favor ou contra um determinado partido.

O G1 também ignorou determinadas regiões do país. Enquanto todos os prefeitos das capitais da região Sul tiveram espaço, nenhum prefeito do Centro-Oeste foi ouvido. Também ficou de fora o estado de Minas Gerais, que possui o maior número de municípios e tem a capital Belo Horizonte como uma das mais importantes do país. Por outro lado, a região Sudeste concentrou a maior parte das entrevistas: além de prefeitos das outras capitais, também foram ouvidos governantes de cidades do interior. Cabe ressaltar que o G1 é um portal com aderência em todo o território brasileiro, com noticiários locais produzidos em todos os estados, o que permitiria contemplar todas as regiões.

Os estudos de enquadramento também consideram o espaço que os atores políticos recebem na cobertura jornalística. Para checar esse quesito, o estudo contou o número total de caracteres de cada entrevista. Assim, foi possível verificar que não houve nenhuma preocupação dos diferentes veículos jornalísticos em equilibrar o espaço dado aos diferentes prefeitos, ao contrário do que usualmente ocorre durante as campanhas eleitorais. Igualmente, não fomos capazes de identificar algum critério quanto ao número de perguntas ou tempo de resposta.

Entman (1993) afirma que muitas vezes o enquadramento noticioso aponta para algum tipo de recomendação ou tratamento para o problema identificado na narrativa. Nossa primeira hipótese (H1) era de que as perguntas tinham como temática a cobrança de resultados, desafiando a imagem desejada pelos prefeitos. De fato, o que constatamos a partir dos componentes enquadrados foi que o portal adotou um viés de contestação, voltado para os compromissos eleitorais. Por isso, termos como prazos, promessas e planos aparecem entre os mais mencionados pelos jornalistas, atingindo todos os partidos. Já entre as áreas de atuação dos governos, a saúde, a mobilidade urbana e a educação aparecem como prioridades dos jornalistas.

Do lado da política, estudos desenvolvidos sobre argumentação demonstram a força do discurso ao dimensionar o mundo, ordenar os fatos e apresentar recortes da realidade. Nossa segunda hipótese apontava que (H2) os prefeitos fariam uso da exposição das entrevistas para promover a própria imagem, criando um clima favorável para o início do governo, o que de fato ocorreu. Foi possível verificar, através dos verbos mais conjugados, que as autoridades buscaram usar expressões afirmativas como forma de projetar uma imagem positiva dos 100 dias de gestão. A escolha de palavras como "estamos", 
"trabalhando", "fazendo" e "conseguindo" buscam imprimir uma sensação de proatividade, confiança e trabalho quanto ao novo ciclo de governo. Portanto, prevaleceu a exortação como tipo de linguagem descrito por Edelman (1994).

Outra peculiaridade é a diferença do tempo verbal em relação às campanhas eleitorais. Nesse caso, os políticos não se referem mais ao futuro, ao que planejam fazer. Nos primeiros meses no cargo, o uso do gerúndio remete ao tempo presente, ao que está em ação. Quanto aos tópicos mais usados, o grande número de menções ao termo "população" indica que os prefeitos estão se comunicando diretamente com seu público-alvo, que agora não são mais os eleitores, mas ao que Charaudeau (2006) chama de instância cidadã.

A escolha do formato entrevista para esta análise se mostrou adequada para o propósito de verificar como os dois campos, mídia e política, tratam a efeméride dos 100 dias de governo. Concluímos que, no lado dos jornalistas, a cobertura teve um viés de cobrança por resultados, focado nas promessas de campanha. Portanto, atuando criticamente para desestabilizar a imagem pretendida pelos prefeitos e para cumprir o seu papel social (LAGE, 2014). Contudo, não observamos nenhum direcionamento ou saliência que favorecesse ou prejudicasse, de maneira intencional e explícita, a imagem de algum prefeito de determinado partido ou espectro ideológico.

Por sua vez, os atores políticos usaram as respostas para projetar através do discurso uma imagem positiva do início do mandato. Nesse caso, demonstraram estar atentos às expectativas da população, com o uso de palavras afirmativas que denotam ação, confiança e otimismo. Portanto, ao serem indagados pelos jornalistas, os prefeitos indicaram estar em campanha permanente pela projeção da imagem mais conveniente para a aprovação da opinião pública tendo como objetivo a obtenção de ganhos políticos futuros.

Por fim, a pesquisa apresenta algumas limitações. Ao focar nos textos, os vídeos e fotos que ilustraram algumas entrevistas ficaram de fora. Além disso, outras categorias poderiam ter sido incluídas, como a identificação dos atores sociais e a tipificação dos discursos. No entanto, consideramos que o essencial foi contemplado levando em conta o nosso objetivo e hipóteses. Pesquisas futuras poderão buscar outras abordagens metodológicas. Os 100 dias de governo se tratam de uma efeméride reconhecida pelos campos midiático e político, porém ainda pouco abordados pelo campo acadêmico brasileiro e podem servir de recorte para uma série de pesquisas empíricas. 


\section{Financiamento}

Capes (Coordenação de Aperfeiçoamento de Pessoal de Nível Superior) e CNPq (Conselho Nacional de Desenvolvimento Científico e Tecnológico).

\section{Referências}

ALTHEIDE, David L. Media logic, social control, and fear. Communication Theory, Cary, v. 23, n. 3, p. 223-238, 2013.

AMARANTE, Erivelto. 0 prefeito gari: uma análise de cobertura dos 100 primeiros dias do governo João Doria em São Paulo. Temática, João Pessoa, v. 17, n. 1, p. 1-17, 2021.

ARENDT, Hannah. 0 que é política. Rio de Janeiro: Bertrand Brasil, 1993.

BENNETT, Lance; ENTMANN, Robert (org.). Mediated politics: communication and the future of democracy. Cambridge: Cambridge University Press, 2001.

BLUMENTHAL, Sidney. The permanent campaign: inside the world of elite political operatives. Boston: Beacon Press, 1980.

BLUMER, Herbert. Symbolic interactionism: perspective and method. Berkeley: University of California Press, 1986.

BLUMLER, Jay G.; GUREVITCH, Michael. The crisis of public communication. London: Routledge, 1995.

BOORSTIN, Daniel J. The image: a guide to pseudo-events in America. New York: Vintage, 2012.

BORGES, Juliano. Webjornalismo político e a cobertura on-line dos 100 primeiros dias de governo Lula. Intexto, Porto Alegre, n. 19, p. 63-80, 2008.

BRANTS, Kees; VAN PRAAG, Philip. Signs of media logic half a century of political communication in the Netherlands. Javnost-The Public, Lyublyana, v. 13, n. 1, p. 25-40, 2006.

CAMPOS, Luiz A. A identificação de enquadramentos através da análise de correspondências: um modelo analítico aplicado à controvérsia das ações afirmativas raciais na imprensa. Opinião Pública, Campinas, v. 20, p. 377-406, 2014.

CASTANHAR, José C. 100 dias do governo Collor: avaliação da reforma administrativa.

Cadernos EBAP, Rio de Janeiro, v. 54, 1990. 
Cem dias de governo, realizações e desafios da gestão. Prefeitura de Aracruz, Aracruz, 12 abr. 2017. Disponível em: http://www.pma.es.gov.br/noticia/7821/. Acesso em: 10 mar. 2021.

CHAMPAGNE, Patrick. Formar a opinião: o novo jogo político. Petrópolis, RJ: Vozes, 1998.

CHARAUDEAU, Patrick. Discurso político. São Paulo: Contexto, 2006.

CODATO, Adriano; BERLATTO, Fábia; BOLOGNESI, Bruno. Tipologia dos políticos de direita no Brasil. Análise Social, Lisboa, v. 53, n. 229, p. 870-897, 2018.

COE, Kevin. The international encyclopedia of political communication. New Jersey: Wiley Black-well, 2015.

DOMINGUEZ, Casey Byrne Knudsen. Is it a honeymoon? An empirical investigation of the president's first hundred days. In: Congress \& the Presidency: A Journal of Capital Studies. Taylor \& Francis Group, 2005. p. 63-78.

Doria apresenta balanço de 100 dias de governo. CBN, São Paulo, 9 abr. 2017. Disponível em: https://glo.bo/2UnxEAk. Acesso em: 10 mar. 2021.

EDELMAN, Murray. The social psychology of politics. In: DODD, Lawrence; JILLSON, Calvin (ed.). The dynamics of american politics: approaches and interpretations. New York: Westview Publisher, 1994. p. 234-251.

Em vídeo, Crivella faz balanço de 100 dias à frente da prefeitura do Rio. 0 Globo, Rio de Janeiro, 7 abr. 2017. Disponível em: https://glo.bo/2CQSPUb. Acesso em: 10 mar. 2021.

ENTMAN, Robert M. Framing: toward a clarification of a fractured paradigm. Journal of Communication, Cary, v. 43, n. 4, p. 51-58, 1993.

FERNANDES, Carla M.; OLIVEIRA, Luiz A.; QUADROS, Ana R. A revanche e os perversos: como Eliane Brum aborda Jair Bolsonaro em sua eleição e nos seus 100 primeiros dias de governo. Disertaciones: Anuario Electrónico de Estudios en Comunicación Social, Rosario, v. 14, n. 1, p. 1-18, 2021.

FRANÇA, Vera R. V. O crime e o trabalho de individuação do acontecimento no espaço midiático. In: CONGRESSO DA SOPCOM, 6., 2009, Lisboa. Anais [...]. Lisboa: Universidade Lusófona, 2009.

GOMES, Wilson. Transformações da política na era da comunicação de massa. São Paulo: Paulus, 2004.

GOMES, Wilson; MAIA, Rousiley. Comunicação e democracia: problemas \& perspectivas. São Paulo: Paulus, 2008.

HUGHES, William J. The not-so-genial conspiracy: The New York Times and six presidential honeymoons, 1953-1993. Journalism \& Mass Communication Quarterly, Columbia, v. 72, n. 4, p. 841-850, 1995. 
KEPPLINGER, Hans M. The international encyclopedia of political communication. New Jersey: Willey Black-well, 2015.

LAGE, Nilson. A estrutura da notícia. 6. ed. São Paulo: Ática, 2006.

LAGE, Nilson. Conceitos de jornalismo e papéis sociais atribuídos aos jornalistas. Pauta Geral, Ponta Grossa, v. 1, n. 1, p. 20-25, 2014.

Leia os planos de Bolsonaro para os 100 primeiros dias de governo. Estadão, São Paulo, 27 dez. 2018. Disponível em: https://politica.estadao.com.br/blogs/coluna-do-estadao/leiaos-planos-de-bolsonaro-para-os-100-primeiros-dias-de-governo/. Acesso em: 10 mar. 2021.

MAIA, Rousiley. Debates públicos na mídia: enquadramentos e troca pública de razões. Revista Brasileira de Ciência Política, Brasília, DF, n. 2, p. 303-340, 2009.

MAZZOLENI, Gianpietro; SCHULZ, Winfried. Mediatization of politics: a challenge for democracy?. Political Communication, Philadelphia, v. 16, n. 3, p. 247-261, 1999.

MENDONÇA, Ricardo F.; SIMÕES, Paula G. Enquadramento: diferentes operacionalizações analíticas de um conceito. Revista Brasileira de Ciências Sociais, São Paulo, v. 27, n. 79, p. 187-201, 2012.

MIGUEL, Luis F. Os meios de comunicação e a prática política. Lua Nova, São Paulo, v. 56, p. 155-184, 2002.

NEUSTADT, Richard E. The contemporary presidency: the presidential hundred days: an overview. Presidential Studies Quarterly, Columbia, v. 31, n. 1, p. 121-125, 2001.

PORTO, Mauro P. Frame diversity and citizen competence: towards a critical approach to news quality. Critical Studies in Media Communication, London, v. 24, n. 4, p. 303-321, 2007.

PREFEITOS falam sobre os 100 dias de gestão. Portal G1, Rio de Janeiro, 10 abr. 2017. Disponível em: http://bit.ly/G1-100dias.

RIZZOTTO, Carla; PRUDENCIO, Kelly; SAMPAIO, Rafael C. Tudo normal: a despolitização no enquadramento multimodal da cobertura do impeachment de Dilma Rousseff.

Comunicação \& Sociedade, São Bernardo do Campo, v. 39, n. 3, p. 111-130, 2017.

RUBIM, Antonio A. C. Espetacularização e mediatização da política. In: RUBIM, Antônio A. C. Comunicação e política: conceitos e abordagens. Salvador: EDUFBA, 2004. p. 181-221.

SÁNCHEZ GALICIA, James (coord.). Treinta claves para entender el poder: léxico de la nueva comunicación política. Ciudad de México: Piso 15, 2010.

WEBER, Maria H. Comunicação e espetáculos da política. Porto Alegre: UFRGS, 2000.

WEBER, Maria H. Imagem Pública. In: RUBIM, Antônio A. C. Comunicação e política: conceitos e abordagens. Salvador: EDUFBA, 2004. p. 259-308. 
WRITEWORDS. Word Frequency Counter. Página inicial. [202-]. Disponível em: www.writewords.org.uk/word_count.asp.

\title{
The public image in the first 100 days of government: a framing analysis of the $\mathbf{G 1}$ portal
}

\begin{abstract}
The first 100 days of government are portrayed by the media as a symbolic date for the beginning of a term of office. Journalism has the habit of scheduling the topic in its news during the period and, more effectively, on the hundredth day. This paper analyzes the series of interviews on the G1 portal with 28 mayors of capitals and metropolitan regions published on April 10,2017 , the exact date of the first 100 days of management. For this, it uses as a theoretical-methodological reference the study of the news framework. The objective is to identify from the interviews which bosses predominate between the fields of media and politics, seeking to understand how journalism appropriates the time frame to frame the interview and which bosses are perceived in the journalists' questions. On the other hand, considering the dependence of political actors for media exposure, we also seek to identify in the political discourse which image the government wants to print at the beginning of the term. The results show that, while journalism uses the period to charge the progress of the campaign proposals, politicians take advantage of the ephemeris to print an image of work, achievement, and optimism.
\end{abstract}

\section{Keywords}

Public image; News framing; 100 days of government; Political speech; Political communication

\section{Autoria para correspondência}

Erivelto Diego Amarante

novo.eri@gmail.com

\section{Como citar}

AMARANTE, Erivelto Diego; SAMPAIO, Rafael Cardoso. A imagem pública nos 100 primeiros dias de governo: uma análise de entrevistas do portal G1 com prefeitos em início de mandato. Intexto, Porto Alegre, n. 52, e-96617, jan./dez. 2021. DOI: http://dx.doi.org/10.19132/1807-8583202152.96617 
Recebido em 21/09/2019

Aceito em 09/06/2021

(c) $(1) \Theta$ 